\title{
HEAD AND NECK
}

\section{Barbed suture in oral cavity reconstruction: preliminary results}

\author{
La sutura barbed nella ricostruzione del cavo orale: risultati preliminari \\ E. CROSETTI' A. CARACCIOLO ${ }^{1}$, G. ARRIGONI¹ , E. DELMASTRO², G. SUCCO ${ }^{1}$ \\ ${ }^{1}$ Head and Neck Oncology Service, Oncology Deparment University of Turin, Candiolo Cancer Institute - FPO, IRCCS, \\ Candiolo (TO), Italy; ${ }^{2}$ Division of Radiotherapy, Candiolo Cancer Institute - FPO, IRCCS, Candiolo (TO), Italy
}

\section{SUMMARY}

The purpose of this study is to evaluate the efficacy and safety of unidirectional barbed suture (V-Loc) compared to a standard monofilament stitch (Vicryl) in suturing of a free flap to local tissue after head and neck surgery for squamous cell carcinoma of the oral cavity. Complication rates, operative closure time, length of hospitalisation and costs were evaluated. The study cohort (group A) of 20 consecutive patients reconstructed using barbed stitches for suturing was prospectively compared to a control cohort (group B) of 20 consecutive patients reconstructed using conventional vicryl stitches. All patients were affected by squamous cell carcinoma of the tongue and underwent different types of glossectomy and reconstruction with free flaps. This analysis demonstrates the efficacy of the barbed suture compared with a standard monofilament stitch in terms of lower complication rate (15\% group A, $30 \%$ group B), intra-operative closure times (486 minutes group A, 517 minutes group B), and length of hospitalisation (average length of hospitalisation 14.60 days group A, 16.85 days group B). These factors coupled with the use of a lower number of stitches compared with the standard stitches may compensate the increased cost of the barbed suture. In conclusion, this study demonstrates that the use of unidirectional barbed stitches for suturing of a free flap to the recipient site reduces the complication rate, principally in terms of dehiscence and fistula incidence, and reduces intra-operative time and length of hospitalisation. Based on these results and on the literature, the use of unidirectional barbed stitches can be considered as a safe and efficient alternative to conventional stitches for suturing of free flaps to local tissue.

KEY WORDS: Barbed suture • Free flap • Head neck reconstruction • Oral cavity cancer

\section{RIASSUNTO}

Il presente studio ha lo scopo di analizzare le potenzialità e la sicurezza della sutura unidirezionale barbed (V-Loc) rispetto alla sutura convenzionale monofilamento (vicryl) nella chirurgia ricostruttiva del cavo orale con lembo libero. Sono stati valutati i seguenti parametri: percentuale di complicanze, tempi intra-operatori, tempi di ospedalizzazione e costi della procedura. La coorte di studio (gruppo A), costituita da 20 pazienti consecutivi in cui è stata utilizzata la sutura barbed per suturare il lembo libero alla mucosa del cavo orale, è stata confrontata con la coorte di controllo (gruppo B), costituita da 20 pazienti consecutivi, in cui è stata invece utilizzata la sutura convenzionale Vycril. Tutti i pazienti, affetti da carcinoma squamocellulare della lingua, sono stati sottoposti a chirurgia compartimentale della lingua e successiva ricostruzione con lembo libero radiale di avambraccio o antero-laterale di coscia. La nostra analisi dimostra l'efficacia della sutura barbed se confrontata con quella convenzionale, in termini di minore percentuale di complicanze post-operatorie (15\% gruppo A, $30 \%$ gruppo B), tempi intraoperatori di chiusura (486 minuti gruppo A, 517 minuti gruppo B), e tempi di ospedalizzazione (tempo medio di ospedalizzazione: 14,60 giorni gruppo A, 16,85 gruppo B). Questi fattori, associati al minor numero di fili barbed utilizzati durante la sutura, potrebbero compensare il costo maggiore della sutura barbed rispetto a quella convenzionale. In conclusione, questo studio dimostra che l'utilizzo della sutura unidirezionale barbed nella sutura del lembo libero alla mucosa del cavo orale riduce la percentuale di complicanze post-operatorie, principalmente in termini di deiscenza e fistola, i tempi intra-operatori e la durata dell'ospedalizzazione. Basandosi su questi risultati e sulla letteratura, si può concludere che l'utilizzo della sutura barbed rappresenta un'alternativa sicura ed efficace rispetto alla sutura convenzionale nella chirurgia ricostruttiva del cavo orale.

PAROLE CHIAVE: Sutura barbed $\bullet$ Lembo libero $\bullet$ Ricostruzione cervico-cefalica $\bullet$ Carcinoma del cavo orale

\section{Introduction}

Since the introduction of reconstruction in head and neck oncology in the 1970s as a mainstay of surgical practice, the use of free flaps has progressively evolved, reaching success rates ranging between $90 \%$ and $98 \%$. To date, mi- crovascular flaps represent the gold standard for reconstruction of complex three-dimensional composite defects in the head and neck district. The main advantages of microvascular reconstructive techniques, compared to less sophisticated ones, are the possibility to choose the best 
defect-adapted tissue, tailor the flap in a three-dimensional fashion to minimise postoperative functional defects and, most importantly, to bring well vascularised tissue into the surgical field to accelerate the healing process. Although in recent decades, surgeons' experience, quality of anaesthesiology techniques and postoperative care have consistently improved, free flap reconstruction of head and neck cancer (HNC) defects remains a complex procedure involving many aspects that can increase the perioperative complication rate (general and local) and potentially affect the final outcome, especially in elderly patients with important comorbidities ${ }^{1}$.

Regarding local complications, the incidence of flap dehiscence and fistula reported in the literature is high. The sutures commonly used to fix the free flap to local tissue in the recipient site include conventional absorbable monofilament, such as vicryl. In recent years, our centre has adopted the barbed suture, a relatively new device with cutting barb that gives tensile strength without the need for tying. There is increasing evidence that knotless, barbed, self-anchoring suture devices are as safe and well tolerated as conventional stitches in tissue suturing and that their use seems to be associated with reduced surgical closure times, local complications and costs ${ }^{2}$.

In our study, we evaluated the efficacy and safety of the unidirectional barbed suture (V-Loc) compared to a standard monofilament stitch (Vicryl) in suturing of free flaps to local tissue after head and neck surgery for squamous cell carcinoma of the oral cavity. Complication rates, operative closure times, length of hospitalisation and costs were evaluated. To our knowledge, this study represents the first analysis of outcomes of barbed sutures applied in reconstructive head and neck surgery.

\section{Materials and methods}

A prospective study was carried out on the use of the barbed suture in the reconstruction of patients affected by squamous cell carcinoma of the tongue who were submitted to different types of glossectomy (subtotal, hemi-glossectomy, marginal glossectomy) and reconstructed with free flaps (radial forearm free flap (RFFF) or anterolateral tight free flap (ALT)).

The study cohort (group A) included 20 consecutive patients treated between 2016 and 2017 in the ENT Department of San Luigi Gonzaga Hospital, Orbassano (Turin) and in the ENT Department of FPO-IRCCS Candiolo Cancer Institute. All patients were reconstructed using barbed stitches for suturing (V-Loc, Covidien, Mansfield, VA, USA).

The control cohort (group B) included 20 consecutive patients treated by the same surgeons between 2014 and 2016 in the ENT Department of Turin, the Martini Hospital and San Luigi Gonzaga Hospital, and reconstructed using conventional Vicryl stitches (vicryl 3.0, Ethicon, Cincinnati, OH, USA).

The characteristics of patients in group A are reported in Table I, and those in group B are reported in Table II. Nine of 40 patients were affected by diabetes mellitus (DM) ( 6 in group A and 3 in group B). Seven patients were pretreated with radiotherapy (RT) (4 in group A and 3 in group B). All patients gave oral and written informed consent preoperatively, following the principles of the Helsinki Declaration, developed in 2013 by the World Medical Association (WMA) as a statement of ethical principles for medical research involving human subjects ${ }^{3}$.

Clinical assessment was performed during the 3 weeks before surgery. This involved clinical examination, biopsy with histological exam, evaluation of nutritional status, Maxillo-Facial and Neck CT /MRI and total body PET scan in the case of advanced stage disease.

Nutritional status of the patients was evaluated with the subjective global assessment (SGA) ${ }^{4}$. The SGA consists of a brief nutritional history (weight loss during the last 2 weeks and 6 months, dietary change, and a short physical examination of subcutaneous fat, muscle mass and fluid balance). It categorises patients as being well nourished (SGA A), moderately (or suspected of being) malnourished (SGA B), or severely malnourished (SGA C).

\section{Surgery}

All patients underwent different types of glossectomy by a submandibular approach, en bloc with ipsilateral/bilateral neck dissection, followed by reconstruction with RFFF or ALT. The types of glossectomy were classified into three categories ${ }^{5}$ : partial glossectomy (less than one third of tongue), hemi-glossectomy (from one third to half of tongue) and sub-total glossectomy (from half to three quarters of tongue).

A variety of surgical approaches are available for resection of a primary tumour in the oral cavity. At the present time, the submandibular approach, combined with the use of the harmonic pincer for resection of the tongue, is currently accepted as an oncologically-viable alternative to the conservative trans-mandibular approach, reducing the rate of complications (dehiscence, fistula, plate exposure, osteitis, lack of osteosynthesis, osteonecrosis) ${ }^{6}$.

The surgeon performs a tracheostomy to bypass the transoral intubation and to isolate the oral cavity. Ipsilateral or bilateral selective/radical neck dissection is performed, depending on the site of the tumour (lateral, median or paramedian) and nodal status. The continuity between $\mathrm{T}$ 
Table I. Patient demographics, group A (barbed suture).

\begin{tabular}{|c|c|c|c|c|c|c|c|c|c|c|}
\hline $\mathbf{N}$ & Sex & $\begin{array}{l}\text { Age } \\
\text { (years) }\end{array}$ & Comorbidities & SGA & TNM & Pre-treatment & $\begin{array}{l}\text { Type of } \\
\text { reconstruction }\end{array}$ & $\begin{array}{l}\text { Intraoperative } \\
\text { length (minutes) }\end{array}$ & $\begin{array}{c}\text { Length of } \\
\text { hospitalisation (days) }\end{array}$ & $\begin{array}{l}\text { No. of } \\
\text { stitches }\end{array}$ \\
\hline 1 & M & 64 & None & $\mathrm{B}$ & cT4aN2c & None & ALT & 600 & 13 & 4 \\
\hline 2 & M & 68 & $\mathrm{DM}$ & B & cT4aN1 & None & ALT & 570 & 12 & 4 \\
\hline 3 & M & 51 & None & $\mathrm{B}$ & rT4aN1 & RT & ALT & 570 & 14 & 4 \\
\hline 4 & M & 46 & None & $A$ & rT2NO & RT & RFFF & 520 & 11 & 3 \\
\hline 5 & $\mathrm{~F}$ & 65 & DM & B & rT3N2b & RT & ALT & 480 & 15 & 4 \\
\hline 6 & M & 51 & None & B & cT3N2b & None & RFFF & 510 & 11 & 3 \\
\hline 7 & $\mathrm{~F}$ & 67 & DM & C & cT3N2b & None & $\mathrm{ALT}$ & 440 & 13 & 4 \\
\hline 8 & M & 53 & None & B & cT2NO & None & RFFF & 450 & 16 & 3 \\
\hline 9 & M & 54 & None & $B$ & cT2N0 & None & RFFF & 430 & 14 & 3 \\
\hline 10 & $\mathrm{~F}$ & 54 & None & B & cT3N2a & None & RFFF & 435 & 11 & 2 \\
\hline 11 & M & 58 & None & B & cT2N1 & None & RFFF & 490 & 22 & 3 \\
\hline 12 & $M$ & 47 & None & A & cT2N1 & None & RFFF & 495 & 15 & 3 \\
\hline 13 & $\mathrm{~F}$ & 60 & None & B & cT2NO & None & ALT & 410 & 15 & 4 \\
\hline 14 & $M$ & 72 & DM & C & cT3NO & None & ALT & 510 & 18 & 4 \\
\hline 15 & $\mathrm{~F}$ & 63 & None & $\mathrm{B}$ & cT3N3b & None & ALT & 500 & 17 & 4 \\
\hline 16 & $M$ & 30 & None & C & cT2NO & None & ALT & 415 & 12 & 3 \\
\hline 17 & M & 78 & None & C & cT3N1 & None & ALT & 470 & 17 & 3 \\
\hline 18 & $\mathrm{~F}$ & 76 & DM & C & cT3NO & None & ALT & 480 & 15 & 3 \\
\hline 19 & $M$ & 61 & None & B & cT3NO & None & RFFF & 485 & 13 & 3 \\
\hline 20 & M & 64 & $\mathrm{DM}$ & $\mathrm{B}$ & rT3NO & S-RT & ALT & 460 & 18 & 3 \\
\hline
\end{tabular}

DM: diabetes mellitus; RT: radiotherapy; SGA: subjective global assessment; S: surgery; RFFF: radial forearm free flap; ALT: anterolateral tight flap.

Table II. Patient demographics, group B (conventional suture).

\begin{tabular}{|c|c|c|c|c|c|c|c|c|c|c|}
\hline N & Sex & $\begin{array}{c}\text { Age } \\
\text { (years) }\end{array}$ & Comorbidities & SGA & TNM & Pre-treatment & $\begin{array}{l}\text { Type of } \\
\text { reconstruction }\end{array}$ & $\begin{array}{l}\text { Intraoperative } \\
\text { length (minutes) }\end{array}$ & $\begin{array}{c}\text { Length of } \\
\text { hospitalisation (days) }\end{array}$ & $\begin{array}{l}\text { No. of } \\
\text { stitches }\end{array}$ \\
\hline 1 & $M$ & 75 & None & C & cT2NO & None & RFFF & 540 & 13 & 15 \\
\hline 2 & M & 42 & None & $A$ & cT2N2c & None & RFFF & 540 & 13 & 17 \\
\hline 3 & $\mathrm{~F}$ & 73 & None & $B$ & cT2NO & None & RFFF & 510 & 14 & 14 \\
\hline 4 & $M$ & 76 & None & C & cT2NO & None & RFFF & 600 & 16 & 14 \\
\hline 5 & M & 58 & None & B & cT3NO & None & ALT & 510 & 19 & 18 \\
\hline 6 & $\mathrm{~F}$ & 66 & None & $B$ & rT3N1 & $\mathrm{RT}$ & ALT & 450 & 20 & 21 \\
\hline 7 & M & 58 & $\mathrm{DM}$ & $B$ & cT2N2C & None & ALT & 510 & 22 & 17 \\
\hline 8 & $\mathrm{~F}$ & 62 & None & B & cT2NO & None & ALT & 420 & 17 & 15 \\
\hline 9 & $\mathrm{~F}$ & 51 & None & $B$ & cT4aNO & None & RFFF & 420 & 17 & 14 \\
\hline 10 & M & 56 & None & $B$ & cT3N2b & None & RFFF & 540 & 21 & 15 \\
\hline 11 & M & 48 & None & $A$ & cT2NO & None & RFFF & 500 & 13 & 15 \\
\hline 12 & $\mathrm{~F}$ & 47 & None & A & rT2NO & $\mathrm{RT}$ & RFFF & 480 & 12 & 13 \\
\hline 13 & M & 60 & $\mathrm{DM}$ & $B$ & cT4aN2c & None & ALT & 555 & 21 & 17 \\
\hline 14 & M & 65 & None & C & cT2N2b & None & RFFF & 490 & 16 & 15 \\
\hline 15 & $M$ & 61 & None & $B$ & rT4aN2b & RT & ALT & 705 & 18 & 18 \\
\hline 16 & $\mathrm{~F}$ & 43 & None & $A$ & cT1N2b & None & RFFF & 600 & 15 & 14 \\
\hline 17 & M & 49 & None & $A$ & cT2NO & None & RFFF & 465 & 21 & 15 \\
\hline 18 & $\mathrm{~F}$ & 65 & DM & $C$ & cT4aNO & None & ALT & 465 & 21 & 21 \\
\hline 19 & M & 52 & None & $B$ & cT3N1 & None & $\mathrm{ALT}$ & 555 & 17 & 15 \\
\hline 20 & M & 21 & None & A & cT2N1 & None & RFFF & 480 & 11 & 16 \\
\hline
\end{tabular}


and $\mathrm{N}$ is preserved sectioning the mylohyoid muscle. With a transoral approach, resection should include at least a 1.5- to $2 \mathrm{~cm}$ margin from the macroscopic border of the cancer. Cold instruments may be inadequate for haemostasis owing to the vascularity of the tongue. Therefore, an ultracision device (Harmonic Focus + Shears, Ethicon) is preferred. Frozen sections are obtained from the mucosal margins and from the depth of the surgical defect to ensure that an adequate excision of the primary tumour has been accomplished.

The intraoral defect is then reconstructed with a radial forearm free flap (RFFF) or anterolateral free flap (ALT), depending on the extent of the intraoral defect, patient characteristics and donor site.

Only two surgeons (GS, EC) performed all of the procedures.

\section{Suture technique}

In group A, the suture between local tissue and free flap was performed with a continuous barbed suture. Using the barbed suture, the closure was started by taking the stitch, passing it into the tissue in the opposite direction from the splay of the barb, allowing the suture to pass easily and running the V-Loc device through the welded loop. When a force is applied in the opposite direction, the barb of the suture grasps the surrounding tissue and ensures that the tissue is retained in place (Fig. 1). Images of the V-Loc suture between lingual tissue and free flap (ALT) after partial glossectomy and the healing process are shown in Figures 2-5.

In group B, the suture was performed with a single interrupted knot, using a conventional vicryl stitch (vicryl 3.0, Ethicon, Cincinnati, OH, USA).

\section{Statistical analysis}

The following parameters were evaluated: complication rates, intraoperative time, length of hospitalisation, number of stitches used and cost of the procedure.

Postoperative complications were divided into major complications requiring surgical re-intervention (partial/total necrosis, haematoma, haemorrhage) and minor complications (fistula, suture dehiscence) requiring only medical dressing.

Intraoperative time, length of hospitalisation and cost of the procedures were evaluated with a t-test. The incidence of complications between the two groups was evaluated with a chi-squared test.

Statistical analysis was performed using PRIMIT Software, version 3.03 (McGraw-Hill. Inc.) with $\mathrm{p}<0.05$ considered as statistically significant.

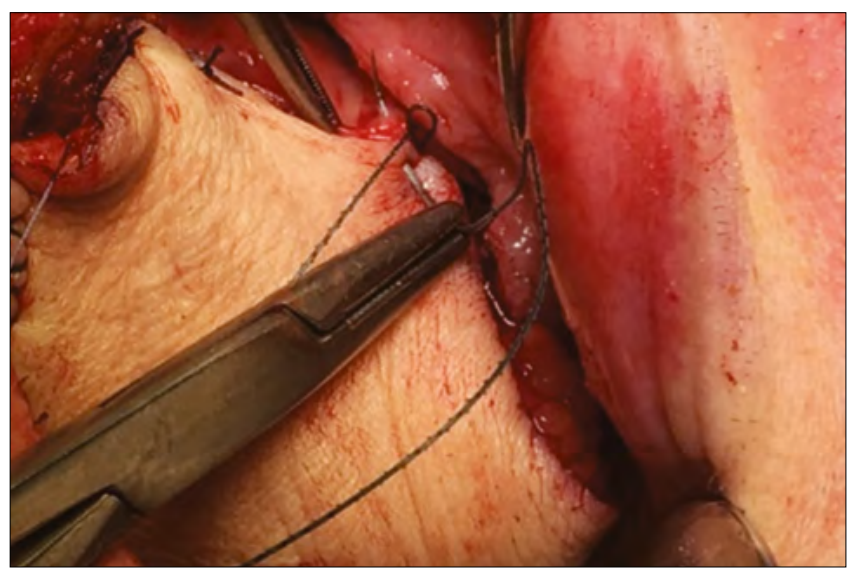

Fig. 1. V-Loc barbed suture.

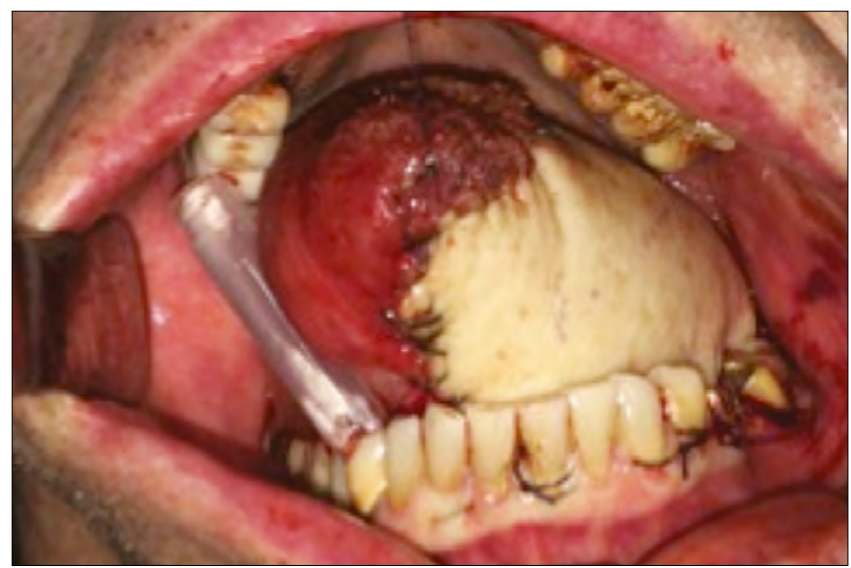

Fig. 2. Intraoperative suture with barbed stitch between lingual tissue and free flap (ALT) after partial glossectomy.

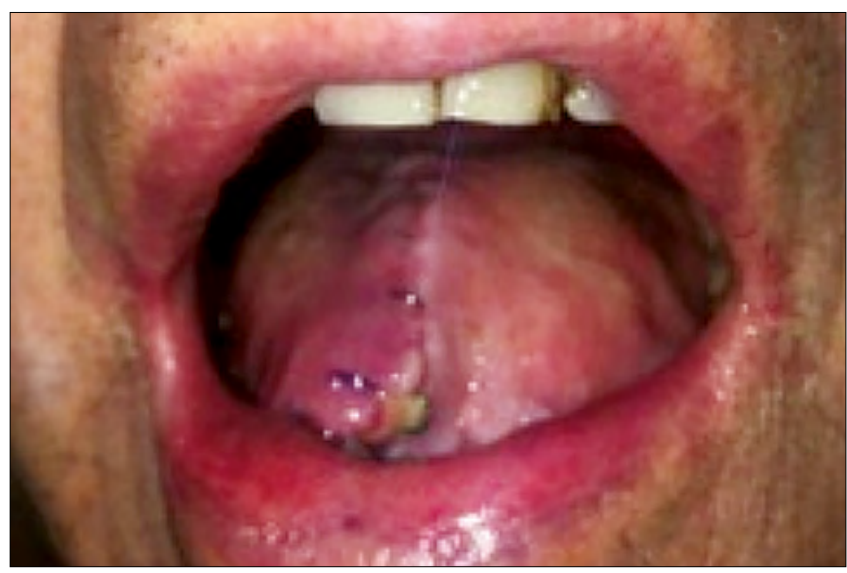

Fig. 3. Barbed suture: 20 days after partial glossectomy.

\section{Results}

A total of 40 patients were treated ( 27 male, 13 female); the median age of group A was 59.1 years (range 2176 years) and 56.4 years in group B (range 30-78 years). 
20 patients were reconstructed with RFFF (8 in group A and 12 in group B), and 20 patients with ALT (12 in group $A$ and 8 in group $B$ ).

\section{Intraoperative time}

The average intraoperative time was 486 minutes for group A and 516.75 minutes for group B. There was no significant difference between groups ( $\mathrm{t}$-test, $\mathrm{p}=0.113$; Table III).

\section{Length of hospitalisation}

The average length of hospitalisation was 14.60 days in group A and 16.85 days in group B. There was a significant difference between groups (t-test, $p=0.03$; Table III).

\section{Cost of the procedure}

The cost of a V-Loc stitch was about $€ 26.60$, while for a vicryl stitch, the cost was $€ 2.50$. The median number of stitches used in the barbed suture was 3.35 , while in the conventional suture was 15.95 . The median cost of the procedure in group A was $€ 89.11$, in group B it was $€ 39.88$ (Table III).

\section{Complication rate}

The incidences of fistula and flap dehiscence were analysed, not considered flap necrosis since this complication could not be related to the type of suture. Subsequently, fistula and dehiscence rates were correlated with three factors: diabetes mellitus, preoperative treatment and nutritional status.

In group A, three patients developed a complication (15\%): two minor complications (10\%) (suture dehiscence with orocutaneous fistula), and one major complication (total necrosis of the flap) (5\%). One of the patients with postoperative fistula was treated with RT before surgery. No patient suffered from diabetes mellitus. The two patients who developed postoperative fistula were moderately (or suspected of being) malnourished (SGA B).

In group $\mathrm{B}$, six patients developed only minor complications $(30 \%)$ (suture dehiscence with orocutaneous fistula): one of these patients was affected by diabetes mel- litus, and none were pretreated before surgery. Three of these patients were well nourished (SGA A), and three were moderately (or suspected of being) malnourished (SGA B).

The overall percentage of procedures without minor complications was 80\%: $90 \%$ in group A and 70\% in group B. Using the chi-squared test, there was no significant difference between the two groups ( $\mathrm{p}$-value $=0.114$ ) $($ Table III). The results are summarised in Table IV.

\section{Discussion}

The goal of head and neck reconstruction is the recovery of important functions (swallowing, speech, chewing) and appearance. Microvascular free tissue transfer techniques have become accepted for head and neck reconstructions because of their increased success rates (95-99\%) and good functional and aesthetic outcomes ${ }^{7}$. Despite progress, the incidence of complications in the literature has continued to be reported as high. Analysing the outcomes after reconstructive surgery in $\mathrm{HNC}$, Pohenz et al. and Bianchi et al. have evaluated the incidence of minor complications of the receiving site and found: flap partial necrosis (29.3\%), dehiscence (27.2\%), haematoma (23.2\%), seroma $(13.4 \%)$ and fistula $(6.9 \%)^{89}$.

In the literature, the reported incidence of fistula is about $20 \%$. In our study, flap dehiscence and fistula were the most common minor complications $(17.5 \%$ overall, $10 \%$ in group A and $30 \%$ in group B). The main risk factors associated with fistula are ascribable to patient-related factors, such as poor nutritional status, systemic conditions that compromise wound healing (diabetes mellitus), previous treatments (radiotherapy and/or chemotherapy) and to surgical site-related factors, such as the clean/contaminated environment of the oral cavity (saliva and bacterial flora), infections, size of the defects after extensive resection and ischaemic complications of the flap ${ }^{10}$. Flap dehiscence with orocutaneous fistula after microvascular tongue reconstruction is a complication that decreases the patient's quality of life, with prolonged hospitalisation and delayed start of adjuvant treatment. Treatment of fistula consists of

Table III. Statistical analysis.

\begin{tabular}{llccc} 
& & Group A & Group B & P-value \\
Average intra-operative time (min) & & 486 & 517 & 0.113 \\
Average length of hospitalisation (days) & & 14.6 & 16.85 & 2.50 \\
& Cost of a stitch (euro) & 26.60 & 15.95 \\
Cost of procedure & Average no. of stitches & 3.35 & 39.88 \\
& Average cost (euro) & 89.11 & 6 & 14 \\
Rate of minor complications & Yes & No & 18 & 114 \\
\hline
\end{tabular}


Table IV. Summary of results.

\begin{tabular}{lccc} 
& Male & $\begin{array}{c}\text { Group A } \\
\text { (barbed } \\
\text { suture) }\end{array}$ & $\begin{array}{c}\text { Group B } \\
\text { (conventional } \\
\text { suture) }\end{array}$ \\
No. of patients & 20 & 20 \\
Gender & Female & 6 & 13 \\
Median age (years) & & 59.1 & 7 \\
Comorbidities & & 6 & 56.4 \\
Pre-treatment (RT) & A & 4 & 3 \\
& B & 14 & 3 \\
SGA & C & 5 & 6 \\
& RFFF & 8 & 10 \\
Free flap & ALT & 12 & 4 \\
Median intra-operative duration (min) & 486 & 12 \\
Median hospitalisation (days) & 14.60 & 817 \\
Complications & Minor & 2 & 16.85 \\
No. of stitches (median) & Major & 1 & 6 \\
Median cost (euro) & & 3.35 & 15.95 \\
\hline RT: radiotherapy; SGA: subjective global assessment; RFFF: radial forearm free flap; \\
ALT: anterolateral tight flap. & & &
\end{tabular}

drainage, no oral intake, dressings and antibiotic therapy ${ }^{11}$. Prevention of fistula must focus on meticulous preoperative multidisciplinary evaluation of the patient. In addition, in our opinion, efforts should be made to improve the suturing technique of the flap to the local tissue, with the goal of providing a watertight closure and therefore better endurance of the suture, and to suture areas that are not easily accessible, such as the base of the tongue, the retromolar area or spaces close to teeth.

In recent years, our centre has used barbed sutures to fix free flaps to local tissue. This is a relatively new device, introduced by John Alcamo in 1964. In recent years, this innovative suture has gained popularity as an alternative to conventional materials, since its approval by the US Food and Drug Administration for soft tissue application in $2005^{12} 13$.

The advent of barbed sutures has given surgeons a new tool for soft tissue suturing. These stitches have begun to revolutionise the field of orthopaedics, plastic surgery, gynaecology, urology and other specialties; however, it has not yet found widespread application in head and neck surgery, apart from pharyngoplasty for obstructive sleep apnoea $^{1415}$.

This particular stitch consists of a permanent suture that has directional projections (or barbs) along its entire length, which imparts tensile strength without the need for tying. The stitch is passed into the tissue in the oppo-

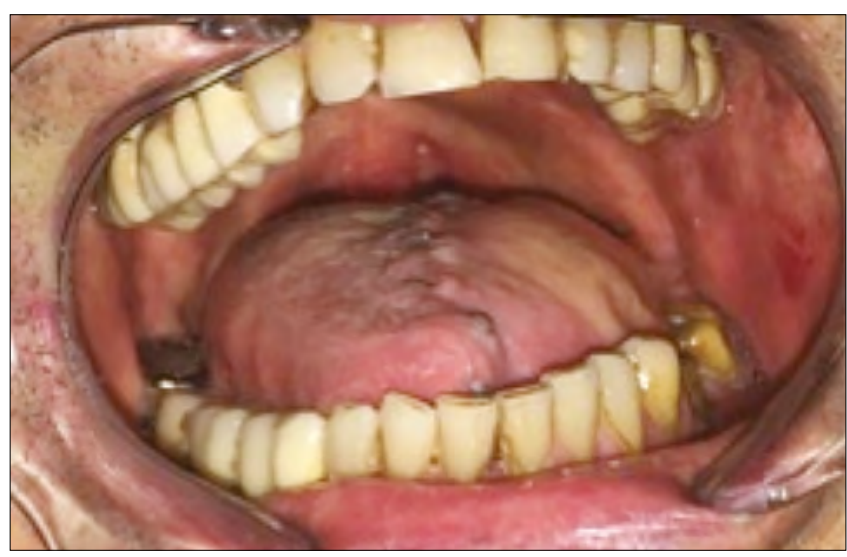

Fig. 4. Barbed suture: Two months after partial glossectomy.

site direction to the splay of the barb, allowing the suture to pass easily. When a force is applied in the opposite direction, the barb of the suture grasps the surrounding tissue and secures the tissue in place ${ }^{16}$. A continuous knotless suture can immediately provide excellent waterproof tightness, reducing saliva infiltration between tissues of different thickness and type. Theoretically, in addition to the closing power of an appropriate flap's volume, the good 3D adaptability and greater vascularisation of the flap, this advantage should represent a substantial improvement over conventional sutures.

Currently, three types of barbed suture are commercially available: the Quill Self-Retaining System (SRS) bidirectional barbed suture (Angiotech, Vancouver, BC, Canada), V-Loc unidirectional barbed suture (Covidien) and Stratafix unidirectional and bidirectional barbed suture (Ethicon) ${ }^{17}$. In our study, we compared the V-Loc barbed suture (group A, study group) with the vicryl 3.0 conventional suture (group B, control group) to suture a free flap to the lingual mucosa. V-Loc is a unidirectional suture with evenly spaced, circumferentially distributed barbs, with a needle on one end and a welded loop on the other.

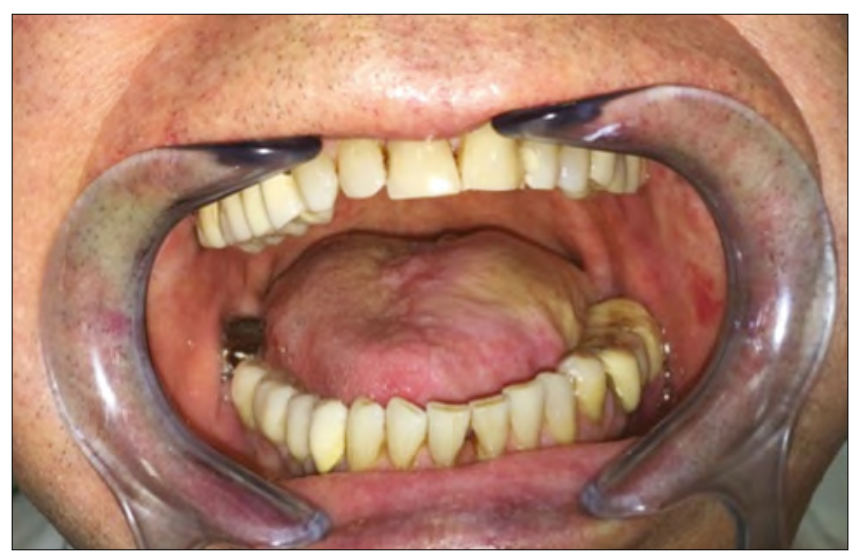

Fig. 5. Barbed suture: six months after partial glossectomy. 
Comparisons between the two groups demonstrated the efficiency of the barbed suture: minor complication rates (suture dehiscence with orocutaneous fistula) were $10 \%$ in group A and 30\% in group B. It is undeniable that the barbed suture shows a trend towards a fewer minor complications, even though our results did not show a significant difference between the two cohorts. This is probably due to the small number of patients in our study.

The advantages of the barbed suture may be due to different factors. This suture could decrease the potential chance of knot-related complications. In conventional stitches, the spaces between filaments of braided sutures act as a nidus for bacteria, exacerbating the risk of infection, ischaemia and necrosis. On the other hand, barbed stitches decrease the potential for knot slippage or dehiscence secondary to knot breakage, suture extrusion or splitting, necrosis caused by tissue strangulation and micro-infarction. Furthermore, the barbed suture provides a continuous suture with multiple anchoring points at each needle entry point, allowing resistance even after an eventual discontinuity, a more uniform distribution of force along the entire length of the stitch, better tissue apposition and better wound healing due to reduction of ischaemia. The tension is more uniformly distributed along the wound and approximation of the tissues is better than with conventional stitches ${ }^{17-19}$.

In addition, the more straightforward and intuitive use of barbed stitches compared with conventional ones allows the surgeon to easily suture even those areas that are difficult to reach, such as the base of the tongue, the retromolar area, or a flap near teeth. Based on these considerations, intraoperative closure times could also be reduced after a normal learning curve, with consequent reduction of intraoperative length, as Paul and colleagues have underlined ${ }^{20}$. Our results confirmed this, with an average intraoperative period of 486 minutes for group A and 516.75 minutes for group B, even though the difference between the two groups was not significantly different (pvalue $=0.113$ ). With a lower incidence of complications and a faster recovery of oral intake, the length of hospitalisation was significantly reduced ( $\mathrm{p}$-value $=0.03$ ).

It is reasonable to think that the learning curve for the barbed suture for skilled surgeons and for those in training is easier and shorter than the conventional one. Vicini et al. studying the learning curve and operative time of the surgical team during pharyngoplasty for OSAHS observed a decrease of these parameters over the course of the study with an initial steep ascent in technical skill acquisition followed by more gradual improvement, and a steady decrease in operative time. The minimally required manipulations and the knotless technique represent for the non-experienced surgeon a technique that is easy to learn, quick and safe to perform, including inside a simultaneous multilevel procedure if required ${ }^{21} 22$.

The main limitation of the barbed suture is its cost; the cost of a vicryl stitch is about $€ 2.50$, while it is $€ 26.60$ for a V-Loc stitch (median cost of the procedure in group A was $€ 89.11$, whereas it was $€ 39.88$ in group B); however, the reduction in intraoperative time, reduction in length of hospitalisation and use of fewer stitches compared with standard ones may offset this increased cost. This idea is supported by a report by Massoud et al. ${ }^{23}$, who performed a cost-effectiveness analysis of robotic-assisted radical prostatectomy using the unidirectional suture compared with the traditional suture and found the former to be more economical ${ }^{22}$.

Obviously, the drawbacks of the barbed device are related to the possibility of extrusion of the suture with its slowly absorbable profile. Furthermore, once the barbs have engaged the tissue, it is almost impossible to remove the stitch, and there is still no recognised procedure for correcting a misplaced suture other than cutting it and starting over again ${ }^{12}$. The barbed suture is stiffer than the conventional one, and this could represent an inconvenience for the patient; for this reason, in our experience, to prevent the patient from feeling discomfort in the oral cavity, it is preferable not to leave the extremity of the thread unrestrained but rather to go back with the suture. Despite the relevance of our findings, the present study has some limitations. It represents two-surgeons and single-institution non-randomised series, so our results cannot be generalised. Moreover, due to the small sample size, statistical analysis is inconclusive and the data will have to be verified in larger, multi-institutional series.

\section{Conclusions}

To our knowledge, this study is the first analysis on the use of the barbed suture compared to conventional ones in the suturing of a free flap to local tissue in head and neck reconstructive surgery, in terms of intraoperative times, costs and complication rates.

The study has demonstrated that the use of unidirectional barbed stitches during the suturing of a free flap to the recipient site reduces the complication rate, principally in terms of dehiscence and fistula incidence. Moreover, the barbed suture is technically easy and safe and may reduce the intraoperative time and consequently the length of hospitalisation. Based on these results and on the findings in the literature, the use of unidirectional barbed stitches can be considered as a safe and efficient alternative to conventional stitches for suturing of free flap to local tissue. 


\section{Acknowledgements}

These researches on oral cancer have been supported by the "ad functionem" grant of the Piedmont Region, years 2015-2018.

\section{Conflict of interest statement}

None declared.

\section{References}

1 Grammatica A, Piazza C, Paderno A, et al. Free flaps in head and neck reconstruction after oncologic surgery: expected outcomes in the elderly. Otolaryngol Head Neck Surg 2015;152:796-802. https:// doi.org/10.1177/0194599815576905.

2 Villa MT, White LE, Alam M, et al. Barbed sutures: a review of the literature. Plast Reconstr Surg 2008;121:102e-108e. https://doi. org/10.1097/01.prs.0000299452.24743.65.

3 General Assembly of the World Medical Association. World Medical Association Declaration of Helsinki: ethical principles for medical research involving human subjects. J Am Coll Dent 2014;81:14-8.

4 Detsky AS, McLaughlin JR, Baker JP, et al. What is subjective global assessment of nutritional status? JPEN J Parenter Enteral Nutr 1987;11:8-13. https://doi.org/10.1177/014860718701100108.

5 Myers LL, Rihani JJ. Glossectomy. MedScape; 2016.

6 Barzan L, Antonio J, Santini S, et al. Submandibular approach and use of the harmonic instrument in lateral oral cavity and oropharyngeal oncologic surgery. Acta Otorhinolaryngol Ital 2010;30:277-80.

7 Koul AR, Patil RK, Nahar S. Unfavourable results in free tissue transfer. Indian J Plast Surg 2013;46:247-55. https://doi. org/10.4103/0970-0358.118600.

8 Pohlenz P, Klatt J, Schon G, et al. Microvascular free flaps in head and neck surgery: complications and outcome of 1000 flaps. Int $\mathrm{J}$ Oral Maxillofac Surg 2012;41:739-43. https://doi.org/10.1016/j. ijom.2012.02.012.

9 Bianchi B, Copelli C, Ferrari S, et al. Free flaps: outcomes and complications in head and neck reconstructions. J Craniomaxillofac Surg 2009;37:438-42. https://doi.org/10.1016/j.jcms.2009.05.003.

10 Akashi M, Kusumoto J, Sakakibara A, et al. Literature review of criteria for defining recipient-site infection after oral oncologic surgery with simultaneous reconstruction. Surg Infect (Larchmt) 2017;18:755-64. https://doi.org/10.1089/sur.2017.101.

11 Al Deek NF, Wei FC, Tsao CK. Fistulae after successful free tissue transfer to head and neck: its prevention and treatment. Clin Plast Surg 2016;43:739-45. https://doi.org/10.1016/j.cps.2016.05.010.

12 Rinaldi V, Mantovani M, Pignataro L. Barbed suture rescue procedure. Aesthet Surg J 2017;37:250-2. https://doi.org/10.1093/asj/ sjw096.

13 Cortez R, Lazcano E, Miller T, et al. Barbed sutures and wound complications in plastic surgery: an analysis of outcomes. Aesthet Surg J 2015;35:178-88. https://doi.org/10.1093/asj/sju012.

14 Mantovani M, Minetti A, Torretta S, et al. The velo-uvulo-pharyngeal lift or "roman blinds" technique for treatment of snoring: a preliminary report. Acta Otorhinolaryngol Ital 2012;32:48-53.

15 Mantovani M, Rinaldi V, Torretta S, et al. Barbed Roman blinds technique for the treatment of obstructive sleep apnea: how we do it? Eur Arch Otorhinolaryngol 2016;273:517-23. https://doi. org/10.1007/s00405-015-3726-2.

16 Shah A, Rowlands M, Au A. Barbed sutures and tendon repair - a review. Hand (NY) 2015;10:6-15. https://doi.org/10.1007/s11552014-9669-z.

17 MoyaAP.Barbedsuturesinbodysurgery. AesthetSurg J2013;33(Suppl 3):57S-71S. https://doi.org/10.1177/1090820X13499577.

18 Mitchell RT, Bengtson BP. Clinical applications of barbed suture in aesthetic breast surgery. Clin Plast Surg 2015;42:595-604. https:// doi.org/10.1016/j.cps.2015.06.003.

19 Shermak MA. The application of barbed sutures in body contouring surgery. Aesthet Surg J 2013;33(Suppl 3):72S-75S. https://doi. org/10.1177/1090820X13499915.

20 Paul MD, Budd M. Evaluating the quill self-retaining system: closure time, cost analysis, and current clinical applications. Plast Surg Pract 2009;30-3.

21 Vicini C, Hendawy E, Campanini A, et al. Barbed reposition pharyngoplasty (BRP) for OSAHS: a feasibility, safety, efficacy and teachability pilot study. "We are on the giant's shoulders". Eur Arch Otorhinolaryngol 2015;272:3065-70. https://doi.org/10.1007/ s00405-015-3628-3.

22 Cammaroto G, Montevecchi F, D'Agostino G, et al. Palatal surgery in a transoral robotic setting (TORS): preliminary results of a retrospective comparison between uvulopalatopharyngoplasty (UPPP), expansion sphinter pharyngoplasty (ESP) and barbed repositioning pharyngoplasty (BRP). Acta Otorhinolaryngol Ital 2017;37:406-9. https://doi.org/10.14639/0392-100X-1321.

23 Massoud W, Thanigasalam R, El Hajj A, et al. Does the use of a barbed polyglyconate absorbable suture have an impact on urethral anastomosis time, urethral stenosis rates, and cost effectiveness during robot-assisted radical prostatectomy? Urology 2013;82:90-4. https://doi.org/10.1016/j.urology.2013.02.002.

Received: March 5, 2018 - Accepted: April 20, 2018

How to cite this article: Crosetti E, Caracciolo A, Arrigoni G, et al. Barbed suture in oral cavity reconstruction: preliminary results. Acta Otorhinolaryngol Ital 2019;39:308-315. https://doi.org/10.14639/0392-100X-2130

Address for correspondence: Erika Crosetti, Head and Neck Oncology Service, FPO IRCCS, Candiolo Cancer Institute, FPO, IRCCS, str. prov. 142, 10060 Candiolo (TO), Italy. Tel.+39 011 9933663. E-mail: erikacro73@yahoo.com 